UDC 661.657:539.89

\author{
M. Hu, J. He, Q. Wang, Q. Huang, D. Yu, Y. Tian*, B. Xu \\ (Qinhuangdao, P. R. China) \\ *fhcl@ysu.edu.cn
}

\title{
Covalent-bonded graphyne polymers with high hardness
}

Eight covalent-bonded graphyne polymers have been proposed using the newly developed USPEX and CALYPSO methods based on the first principle calculations. These polymers are energetically more favorable than the corresponding graphyne under ambient pressure, and seven of them are more stable than fullerene $C_{60}$, indicating their existence possibilities. The mechanical and dynamic stabilities of these crystal structures have been confirmed by calculating their elastic constants and phonon dispersion curves, respectively. The newly developed variable-cell nudged elastic band (VC-NEV) simulations show that the graphyne $\rightarrow$ polymer transformation exhibits lower energy barrier than the graphite $\rightarrow$ diamond transformation. Two of the graphyne polymers have been found to be superhard, and the others are hard materials. These graphyne polymers possess tunable electronic properties from metallic to semiconductive.

Keywords: graphyne polymers, hard, electronic characteristics.

\section{INTRODUCTION}

Since the advent of fullerene $\mathrm{C}_{60}$, novel carbon allotropes with fascinating properties are of great interest in both fundamental science and advanced technology, illustrating their unique significance overwhelmingly. Apart from the natural graphite and diamond, attractive and aesthetically pleasing carbon architectures (including fullerene, carbon nanotubes (CNTs), graphene, graphyne, and graphdiyne) are developed as revolutionary materials for further radio frequency logic devices, thermally and electrically conductive reinforced composites, sensors, and transparent electrodes. Research regarding exotic carbon materials with desired and improved properties, such as high hardness, appreciable mechanical strength, metallicity, and semiconductivity with narrow band gap, is always a priority.

Hardness governs the technological development of numerous materials. Hard materials offer a viable strategy towards applications in many fields, including wear-resistance coating, abrasives, and cutting and polishing tools. Therefore, designing and synthesizing novel hard and superhard materials are highly anticipated. These efforts concentrate in two areas, i.e., light element compounds in $\mathrm{B}-\mathrm{C}-\mathrm{N}-\mathrm{O}$ system with short and strong three-dimensional (3D) covalent bonds and compounds fabricated by light elements (B, C, N, and O) and heavy transformation metals with high valence electron densities [1,2]. Currently, diamond is known to be the hardest material in the field of industry. Soft graphite can be converted to superhard diamond without catalysts at extremely high pressure above 15 GPa with temperature above $1500^{\circ} \mathrm{C}$ or above $70 \mathrm{GPa}$ under cold compression [3-5]. Other carbon allotropes are more readily transformed into superhard carbon 
materials. For instance, fullerene $\mathrm{C}_{60}$ can polymerize to 3D superhard carbon phase above $13 \mathrm{GPa}$; in addition, CNTs are transformed into diamond-like carbon allotropes at 8.5-9 GPa pressure and further compressed into an $s p^{3}$-hybridization bonded superhard carbon phase under 16 GPa [6-9]. Compared with stable graphite, metastable carbon allotropes are growing into new precursors for synthesizing hard carbon materials under moderate conditions.

Graphyne and graphdiyne are two nonconventional forms of flat carbon networks with $s p$ - and $s p^{2}$-hybridized carbon atoms $[10,11]$. Graphyne (graphdiyne) is visually fabricated by replacing partial or entire carbon bonds in graphene by randomly distributed acetylenic linkages (diacetylenic linkages). The synthesis of graphyne fragment and large graphdiyne film emphasizes their research significance $[12,13]$. The introduction of acetylenic linkages softens graphyne, which results in lower Young's modulus, shear modulus, and layer modulus compared with graphene, CNTs, and fullerene [14]. Given the strengthening evolutions of graphite $\rightarrow$ diamond and fullerene $\rightarrow$ polymers, graphyne is expected to be strengthened by stacked into 3D graphite-like graphyne; in this process, neighboring graphyne layers are joined via Van der Waals force. In addition, graphyne is also assumed to be strengthened by polymerization into covalentbonded graphyne polymer, where graphyne layers are wrinkled and interlayers are buckled by covalent bonds. Graphite-like graphyne is softer than graphite but exhibits the same large elastic anisotropy [15]. Electronically, these materials can be semimetals, or exhibit doubled Dirac cones, which can be tuned by an electric field with a narrow gap, or can intrinsically possess narrow band gaps [15-17]. Further investigations show that graphite-like graphyne can act as lithium ion battery anode [18]. However, covalent-bonded graphyne polymer has been rarely studied. Recently, two covalent-bonded graphyne polymers are designed theoretically and are predicted to be hard and brittle; these polymers also exhibit tunable electronic properties $[19,20]$. Considering the diversity of graphyne, more covalent-bonded graphyne polymers are expected.

In the present study, we proposed eight novel carbon allotropes by the recently developed ab initio evolutionary algorithm USPEX and CALYPSO, which are designed for crystal structure prediction [21, 22]. These materials are covalentbonded graphyne polymers that are formed via layer by layer folding and buckling perpendicular to the graphyne layer. This transformation mechanism is similar to that of graphite $\rightarrow$ diamond. However, the energy barriers of the transformation from graphite-like graphynes at zero pressure are $0.12-0.34 \mathrm{eV} /$ atom, which are lower than that of graphite $\rightarrow$ diamond. These covalent-bonded graphyne polymers are energetically more favorable than the corresponding graphyne and most of them are even more stable than fullerene $\mathrm{C}_{60}$. The mechanical and dynamic stabilities are confirmed by elastic constants and phonon dispersion curves, respectively. Electronic band structure calculations indicate that covalent-bonded graphyne polymers possess tunable electronic properties from semimetallic to semiconductive properties with large band gaps. Covalent-bonded graphyne polymers show remarkably appreciable mechanical properties, such as high hardness, high Young's modulus, and high bulk modulus. Superior properties suggest their promising applications in various fields, including microelectronic devices, energy storage, wear-resistant coating, abrasives, and cutting and polishing tools. Our research broadens our understanding of designing and synthesizing hard and superhard materials; moreover, our research provides insights into the significance of graphyne. 


\section{CALCULATION METHODS}

Crystal structure prediction methods, USPEX and CALYPSO, are employed to design reasonable carbon allotropes [21, 22]; these methods have been successfully applied to construct various valid carbon polymorphs [23-26]. Structural searches were conducted up to 24 atoms/cell within the $0 \mathrm{GPa}$ to $25 \mathrm{GPa}$ pressure range. Structural relaxations were performed using the CASTEP code [27]. The Vanderbilt ultrasoft pseudopotential was used at the chosen plane-wave cutoff energy of $310 \mathrm{eV}$ [27]. Structural relaxation is completed when the maximum energy change, the maximum force, the maximum stress, and maximum ionic

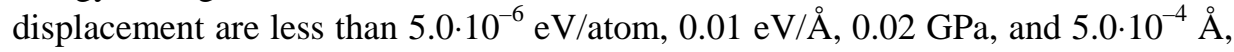
respectively. The exchange correlation terms were treated using the method described by Ceperley and Alder as parametrized by Perdew and Zunger (CA-PZ) form of local density approximation (LDA) [28, 29]. A k-point separation $\left(2 \pi 0.04 \AA^{-1}\right)$ was assigned to generate a k-point grid using the Monkhorst-Pack grid parameters [30]. The linear response method [31, 32] and finite displacement method [27] were used to calculate the phonon frequencies of semiconductive and metallic carbon allotropes, respectively. The variable-cell nudged elastic band (VC-NEB) method provides a broad way to find minimum energy path and investigate the activation pathways between the given initial and end phases for a phase transformation process; the VC-NEB is used in estimating the transformation energy barrier under ambient pressure [33].

\section{RESULTS AND DISCUSSION}

Fabricated graphyne alternatively contains neighboring benzene rings because of the position and ratio of acetylic linkage $(-\mathrm{C} \equiv \mathrm{C}-$ ) inserted into graphene. For convenience, graphyne without neighboring benzene rings is named $\alpha, \beta, \gamma$ graphyne [10] and others are named g-graphyne [34]. The phase transformations of 6,6,6-graphyne, 10,10,10-graphyne, 14,14,14-graphyne, 18,18,18-graphyne, ggraphyne-I, and g-graphyne-II are analyzed (Figs. 1 and 2, Table 1). Under appropriate pressure or other external dynamics, 2A graphite-like 10,10,10graphyne (see Fig. 2, c) is wrinkled and buckled perpendicular to the graphyne layers, thereby forming a monoclinic carbon structure with 16 atoms in a unit cell (dubbed mC16-carbon, as shown in Fig. 1, $a$ ). The sp-hybridized carbon atoms in $10,10,10$-graphyne (marked gray spheres in Fig. $2, c$ ) are polymerized to $s p^{2}$ hybridized atoms in mC16-carbon, whereas the original $s p^{2}$-hybridized atoms in the graphyne (marked black spheres) transform into $s p^{3}$-hybridized atoms after polymerization. Three kinds of bonding modes are present (i.e., $s p^{2}-s p^{2}, s p^{2}-s p^{3}$, and $s p^{3}-s p^{3}$ ) in mC16-carbon. Two $s p^{2}-s p^{2}$ bonds with lengths of $1.409 \AA$ and $1.379 \AA$ are a little shorter than the $s p^{2}-s p^{2}$ bond in graphene (1.42 $\AA$ ). The equal length of $s p^{3}-s p^{3}$ bonds $(1.564 \AA)$ approaches to that in diamond (1.54 $\AA$ ); whereas the length of $s p^{2}-s p^{3}$ bonds $(1.484 \AA)$ is measured between these bonds. Similar polymerization changes occur in $o P 12$-carbon and $h P 12$-carbon from g-graphyneII and 6,6,6-graphyne, respectively. However, in g-graphyne-I $\rightarrow$ tP6-carbon [35], half $s p^{2}$-hybridized atoms in graphyne transform into $s p^{3}$-hybridized atoms and the rest are preserved in the continuous benzene ring chains. By contrast, the $s p$ hybridized atoms in graphyne exclusively change into $s p^{2}$-hybridized atoms. Hence, $t P 6$-carbon contains only $s p^{2}-s p^{2}$ and $s p^{2}-s p^{3}$ bonds. One graphyne is readily assembled into diverse covalent-bonded graphyne polymers because of different wrinkling and buckling manners of graphyne layers. The $h P 16$-carbon [36] and oI16-carbon are both 18,18,18-graphyne products. In two polymorphs, the 
initial $s p$-hybridized carbon atoms transform into $s p^{2}$-hybridized atoms, and the initial $s p^{2}$-hybridization transforms into $s p^{3}$-hybridization. The differences between these hybridized atoms originate from the different wrinkles of graphyne sheet before the interlayer buckling. According to the same principle, 14,14,14-graphyne can alternatively transform into either oC12-carbon or oC24-carbon.

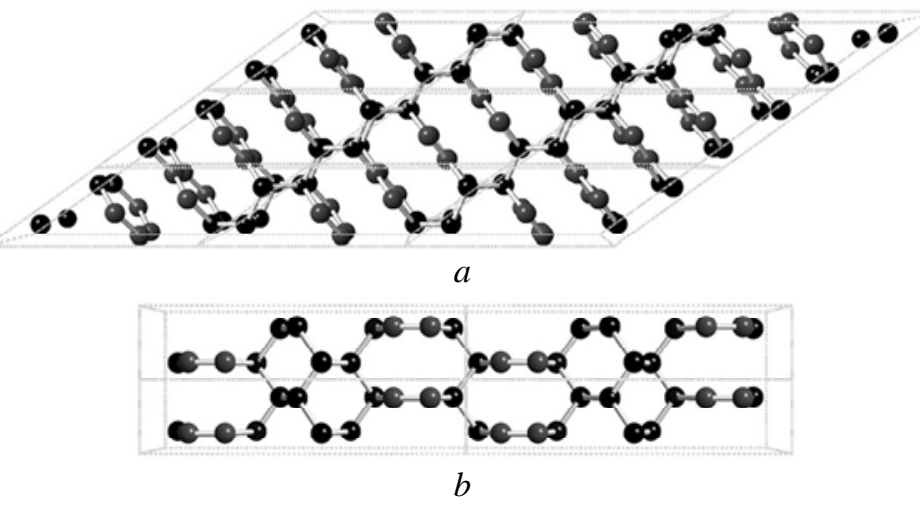

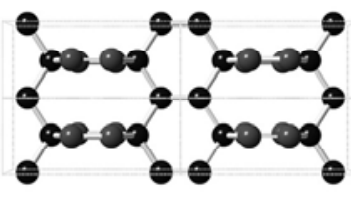

C
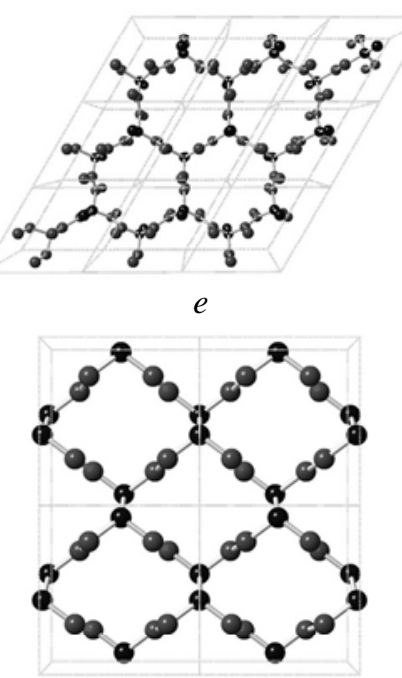

g
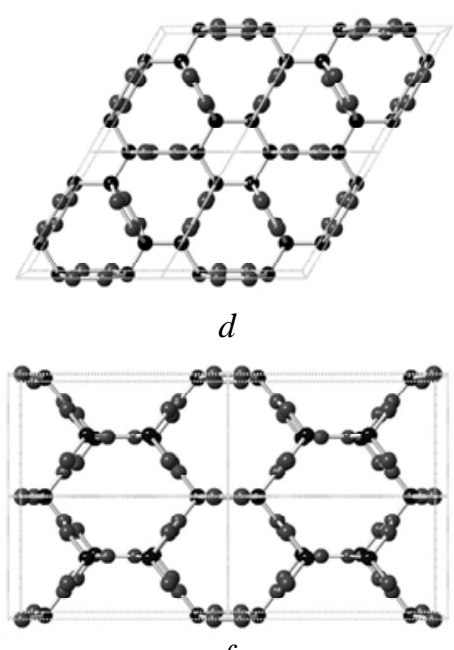

$f$

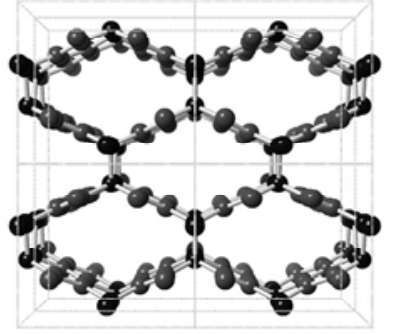

$h$

Fig. 1. Optimized crystal structures of covalent-bonded graphyne polymers perpendicular to the graphyne layer. Plate (a) $3 \times 1 \times 3$ supercell of mC16-carbon, (b) $2 \times 1 \times 2$ supercell of $o P 12$-carbon, (c) $1 \times 2 \times 2$ supercell of $t P 6$-carbon, $(d) 2 \times 2 \times 1$ supercell of $h P 12$-carbon, $(e) 3 \times 3 \times 1$ supercell of $h P 16$-carbon, $(f) 2 \times 2 \times 1$ supercell of oI16-carbon, $(g) 2 \times 2 \times 1$ supercell of $o C 12$-carbon, $(h)$ $2 \times 2 \times 1$ supercell of $o C 24$-carbon. The gray spheres represent the carbon atoms transformed from the $s p$-hybridized atoms in corresponding graphyne, and the black ones represent the carbon atoms transformed from the $s p^{2}$-hybridized atoms in graphyne. The polymers (e.g., $m C 16$ carbon) are named after the crystal system (monoclinic), space group $(C 2 / m)$, and carbon atom number in a unit cell (16). 


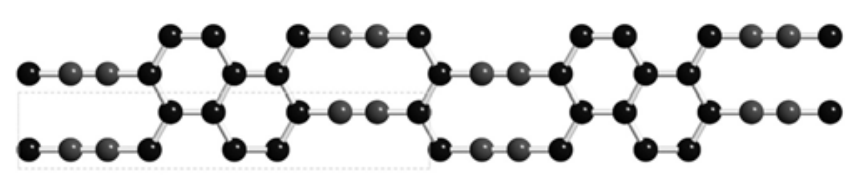

$a$
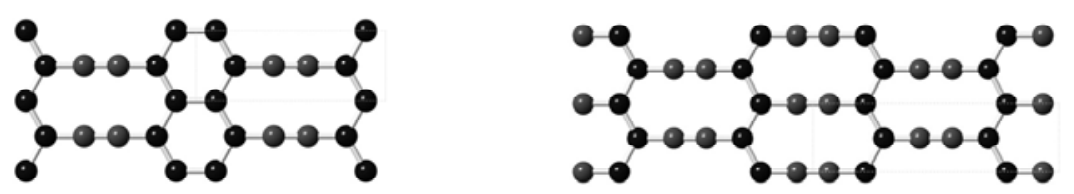

b

$C$

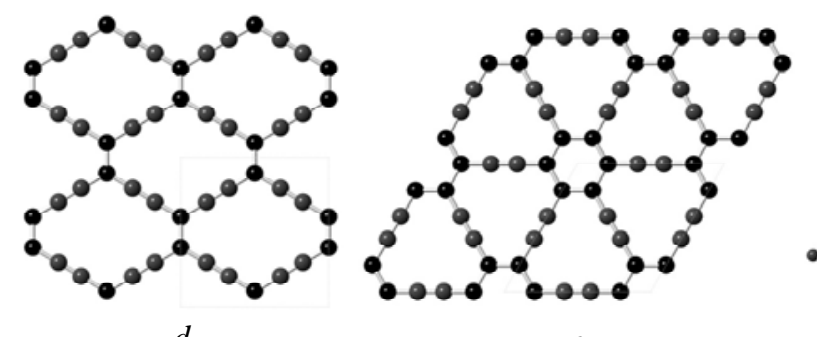

$d$

$e$

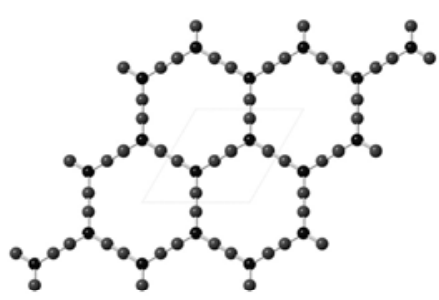

$f$

Fig. 2. Optimized crystal structures of graphynes. Plate $(a)$ g-graphyne-II, $(b)$ g-graphyne-I, $(c)$ 10,10,10-graphyne, (d) 14,14,14-graphyne, (e) 6,6,6-graphyne, ( $f$ ) 18,18,18-graphyne. The gray spheres represent the $s p$-hybridized carbon atoms, and the black ones represent the $s p^{2}$-hybridized atoms.

Table 1. Parent graphyne, space group (S.G.), cell parameters (C.P.), and atomic Wyckoff positions of covalent-bonded graphyne polymers

\begin{tabular}{c|c|c|c|c}
\hline Structure & Graphyne & S.G. & C.P., $\AA$ & Atomic positions \\
\hline tP6-carbon & g-graphyne-I & $P 42 / m m c$ & $a=2.563$ & $4 i(-1.000,-1 / 2,-0.612)$ \\
& & & $c=5.929$ & $2 f(-1 / 2,1 / 2,-1.250)$ \\
oC12-carbon & 14,14,14-graphyne & Cmcm & $a=5.875$ & $8 g(-0.205,-0.284,1.250)$ \\
& & & $b=6.195$ & $4 c(-1.000,-0.572,3 / 4)$ \\
& & & $c=2.443$ & \\
hP12-carbon & 6,6,6-graphyne & P6/mmm & $a=6.155$ & $6 k(0.258,1.000,1 / 2)$ \\
& & & $c=2.476$ & $6 j(0.608,0.608,2.000)$ \\
oP12-carbon & g-graphyne-II & \multirow{2}{*}{ Pmma } & $a=2.567$ & $2 e(3 / 4,-2.000,0.617)$ \\
& & & $b=2.488$ & $2 e(3 / 4,-1.000,0.042)$ \\
& & & $c=11.267$ & $2 e(3 / 4,-1.000,0.303)$ \\
& & & & $2 f(3 / 4,-2.500,0.539)$ \\
& & & & $2 f(3 / 4,-1.500,0.231)$ \\
hP16-carbon & 18,18,18-graphyne & P63/mmc & $a=6.777$ & $12 k(0.450,0.550,0.914)$ \\
& & & $c=4.219$ & $4 f(1 / 3,2 / 3,0.433)$ \\
oI16-carbon & 18,18,18-graphyne & \multirow{2}{*}{ Immm } & $a=10.474$ & $4 f(-0.642,1 / 2,0)$ \\
& & & $b=5.853$ & $8 n(-0.730,0.705,0)$ \\
& & & $c=2.454$ & $4 e(-0.563,1 / 2,1 / 2)$ \\
\hline
\end{tabular}


Table 1. (Contd.)

\begin{tabular}{|c|c|c|c|c|}
\hline \multirow[t]{4}{*}{ mC16-carbon } & 10,10,10-graphyne & $C 2 / m$ & $a=5.144$ & $8 j(-0.244,0.318,-0.087)$ \\
\hline & & & $b=4.241$ & $8 j(0.909,0.337,0.629)$ \\
\hline & & & $c=7.997$ & \\
\hline & & & $\beta=144.369^{\circ}$ & \\
\hline \multirow[t]{3}{*}{ oC24-carbon } & 14,14,14-graphyne & $\mathrm{Cmcm}$ & $a=6.974$ & $16 h(-0.328,-0.213,0.586)$ \\
\hline & & & $b=6.485$ & $8 f(-1 / 2,-0.121,0.433)$ \\
\hline & & & $c=4.195$ & \\
\hline
\end{tabular}

For a theoretically designed crystal structure, structural stability is the first property that needs to be researched among other properties. We have checked the mechanical and dynamic stabilities of those covalent-bonded graphyne polymers by calculating their elastic constants and phonon dispersions, respectively. For a mechanically stable crystal structure, its independent elastic constants should satisfy the generalized Born stability criteria [37]. The calculated elastic constants $C_{i j}$ (Table 2) of the eight structures clearly meet the mechanical stability criteria, which suggests their mechanical stabilities at ambient pressure. The appearance of imaginary phonon frequency means that the structure cannot exist at ambient pressure. The phonon curves of all covalent-bonded graphyne polymers (except the previously proposed $t P 6$-carbon, $o C 12$-carbon, and $h P 16$-carbon) are summarized in Fig. 3. No imaginary phonon frequency is evidently detected in the whole Brillouin zone for the five novel structures, which demonstrates the dynamic stabilities of those carbon polymorphs.
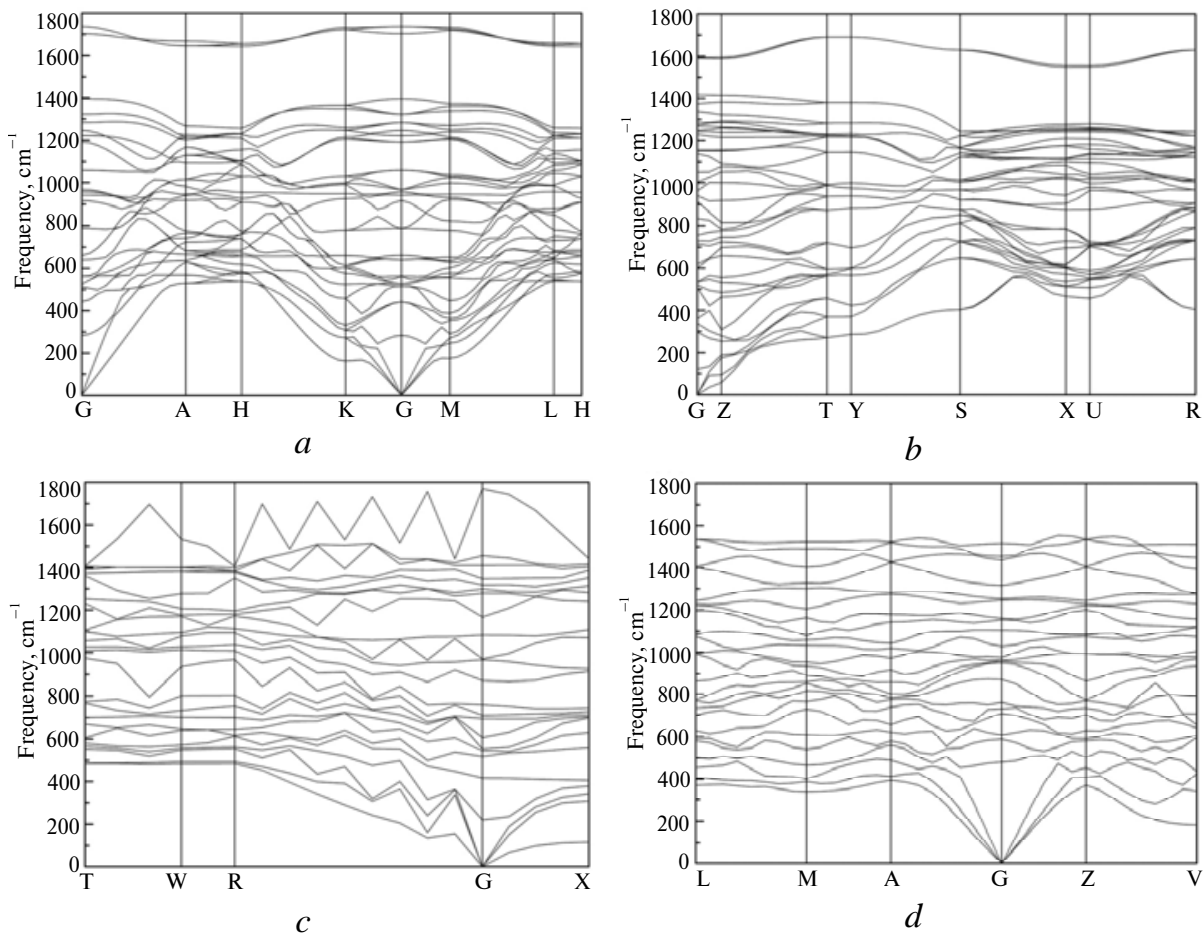

Fig. 3. Simulated phonon dispersion curves of (a) hP12-carbon, (b) oP12-carbon, (c) oI16carbon, (d) $m C 16$-carbon, and (e) oC24-carbon at ambient pressure. 


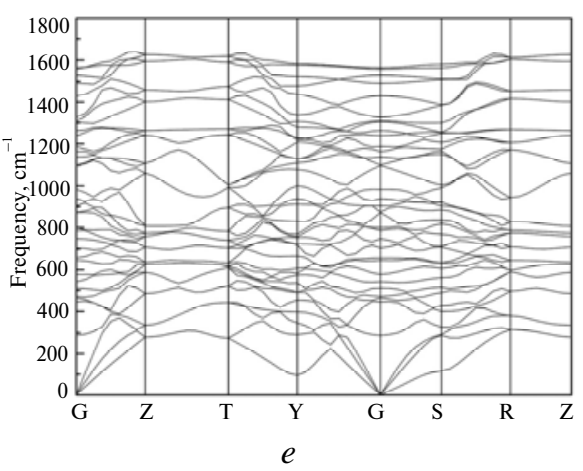

Fig. 3. (Contd.)

Table 2. Simulated elastic constant $\left(C_{i j}\right)$, bulk modulus $(B)$, shear modulus $(G)$, and $B / G$ value of carbon allotropes under ambient pressure

\begin{tabular}{|c|c|c|c|c|}
\hline Structure & $C_{i j}, \mathrm{GPa}$ & $B, \mathrm{GPa}$ & G, GPa & $B / G$ \\
\hline diamond & $C_{11}=1092.4, C_{44}=595.6, C_{12}=135.6$ & 454.5 & 545.6 & 0.83 \\
\hline tP6-carbon & $\begin{array}{c}C_{11}=740.9, C_{33}=1196.2, C_{44}=114.1, C_{66}= \\
64.6, C_{12}=44.0, C_{13}=99.3, C_{16}=0\end{array}$ & 341.1 & 175.9 & 1.94 \\
\hline oC12-carbon & $\begin{array}{c}C_{11}=488.9, C_{22}=360.3, C_{33}=1192.7, C_{44}= \\
274.2, C_{55}=316.0, C_{66}=291.7, C_{12}=287.8, \\
C_{13}=84.4, C_{23}=56.5\end{array}$ & 304.3 & 231.7 & 1.31 \\
\hline hP12-carbon & $\begin{array}{c}C_{11}=641.8, C_{33}=1102.3, C_{44}=264.2, C_{12}= \\
247.4, C_{13}=50.5\end{array}$ & 339.8 & 266.6 & 1.27 \\
\hline oP12-carbon & $\begin{array}{c}C_{11}=773.6, C_{22}=1215.0, C_{33}=1159.4, C_{44}= \\
544.2, C_{55}=114.4, C_{66}=221.2, C_{12}=6.2, C_{13}= \\
73.8, C_{23}=151.3\end{array}$ & 389.9 & 314.2 & 1.24 \\
\hline hP16-carbon & $\begin{array}{c}C_{11}=254.0, C_{33}=764.2, C_{44}=200.8, C_{12}= \\
197.8, C_{13}=71.7\end{array}$ & 207.5 & 103.4 & 2.01 \\
\hline oI16-carbon & $\begin{array}{c}C_{11}=415.4, C_{22}=217.1, C_{33}=922.1, C_{44}= \\
153.0, C_{55}=247.7, C_{66}=49.4, C_{12}=217.9, \\
C_{13}=65.3, C_{23}=56.0\end{array}$ & 219.9 & 127.7 & 1.72 \\
\hline mC16-carbon & $\begin{array}{c}C_{11}=643.1, C_{22}=1143.8, C_{33}=579.4, \\
C_{44}=314.2, C_{55}=367.1, C_{66}=359.5, C_{12}= \\
150.5, C_{13}=289.0, C_{15}=191.5, C_{23}=70.7, C_{25} \\
=73.5, C_{35}=107.6, C_{46}=171.8\end{array}$ & 347.5 & 290.5 & 1.20 \\
\hline oC24-carbon & $\begin{array}{c}C_{11}=617.1, C_{22}=182.6, C_{33}=1009.0, C_{44}= \\
149.3, C_{55}=392.2, C_{66}=133.4, C_{12}=216.4 \\
C_{13}=149.0, C_{23}=42.2\end{array}$ & 225.6 & 178.2 & 1.27 \\
\hline
\end{tabular}

Thermodynamic stability can be estimated by comparing the energy of proposed structures with existed structures (Fig. 4). At ambient pressure, graphite is the most stable carbon allotrope, and fullerene $\mathrm{C}_{60}$ is metastable with higher energy (0.39 eV/atom) relative to graphite. As the diacetylenic linkage is introduced, $2 \mathrm{~A}$ graphite-like graphdiyne possesses the highest energy with $0.90 \mathrm{eV} /$ atom higher than graphite. 2A graphite-like g-graphyne-I, g-graphyne-II, 6,6,6-graphyne, and 10,10,10-graphyne are energetically more favorable than graphdiyne. Our proposed covalent-bonded graphyne polymers are energetically more stable than corresponding graphynes. All polymers except the recently proposed $t P 6$-carbon 
have higher energetic stabilities than $\mathrm{C}_{60}$, and $o C 12$-carbon possesses the lowest energy. Given the low energies of our designed covalent-bonded graphyne polymers, such polymers are highly recommended to be synthesized from graphyne or from some other high energy carbon allotropes.

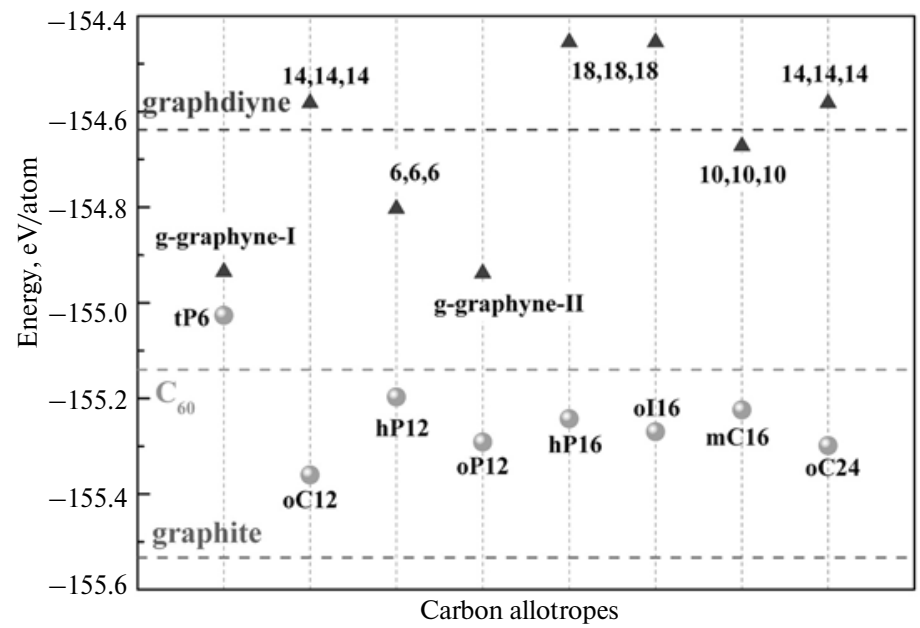

Fig. 4. Calculated ground-state energies of covalent-bonded graphyne polymers and the corresponding $2 \mathrm{~A}$ graphite-like graphyne relative to graphite, $\mathrm{C}_{60}$, and graphdiyne.

Synthesis of metastable carbon phases depends on two important aspects of the transformation process, i.e., the energies of the initial and final states and the transformation energy barrier [38]. Although the energies of covalent-bonded graphyne polymers are lower than that of the corresponding graphynes, a critical issue in rationalizing such phase transformation is pertinent to the transformation energy barrier. The transformation is estimated through the recently developed VC-NEB method.

Graphite is the most stable carbon allotrope at ambient pressure. Extremely high pressure and temperature are demanded to transform graphite into diamond because of the high energy barrier. Recent theoretical calculations illustrate that metastable carbon precursors (e.g., CNTs) more readily transform into novel carbon phases with fascinating properties under moderate pressure conditions because of the lower energy barrier [38]. This understanding can be generalized to the high energy graphyne. In the current study, 2A graphite-like graphynes are employed in calculating the phase transformation energy barrier under ambient pressure (Fig. 5). The bidirectional energy barrier from g-graphyne-I to $t P 6$-carbon is $0.249 \mathrm{eV} /$ atom, and $0.349 \mathrm{eV} /$ atom for the reverse process. The former is lower than the $0.26-0.33 \mathrm{eV} /$ atom from graphite to diamond and the latter is higher than $0.288 \mathrm{eV} / \mathrm{atom}$ for the reverse process [38-39]. This finding indicates that $t P 6-$ carbon is easier to be obtained and quenched under appropriate pressure. The 6,6,6graphyne $\rightarrow h P 12$-carbon transformation encounters the highest energy barrier of $0.339 \mathrm{eV} /$ atom. This value is comparable with that of graphite $\rightarrow$ diamond. Although $o C 12$-carbon is energetically more stable than oC24-carbon, the latter is easier to be obtained because the energy barrier of 14,14,14-graphyne $\rightarrow o C 24$ carbon is lower than that of $14,14,14$-graphyne $\rightarrow$ oC12-carbon. Similarly, energetically inferior $h P 16$-carbon possesses lower phase transformation energy barrier than oI16-carbon from 18,18,18-graphyne. 

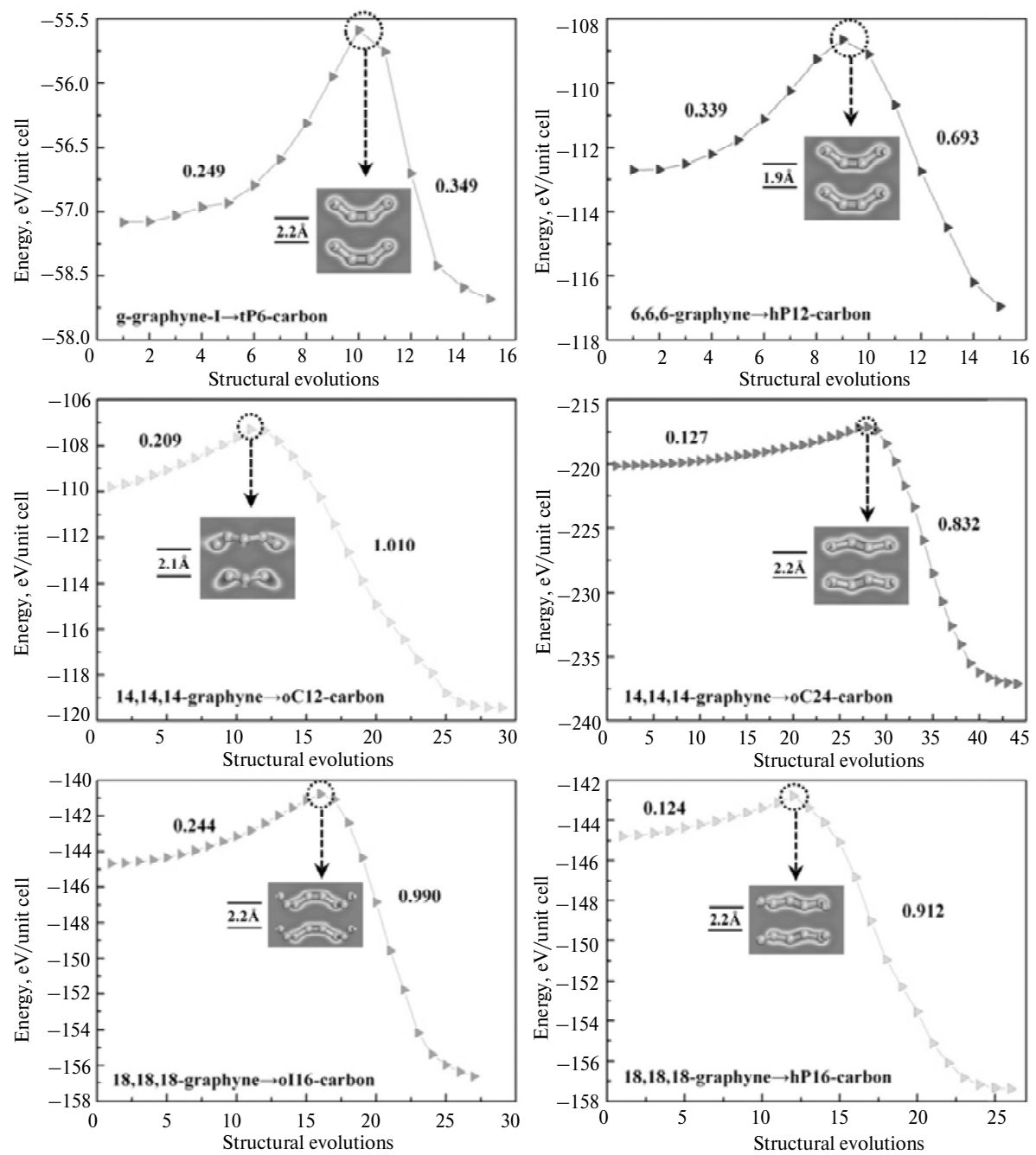

Fig. 5. Bidirectional energy barrier curves from 2A graphite-like graphynes to covalent-bonded graphyne polymers at ambient pressure. Inserts show the electron density profiles corresponding to the curve peaks.

Our investigations show that the graphyne is still in graphite-like model with inter-layer distance of 1.9-2.2 $\AA$ at the energy barrier peak (inserts in Fig. 5). Similar results are also observed in the transformation of graphite $\rightarrow$ diamond and CNTs $\rightarrow$ 3D polymers [38]. Interestingly, the graphene layer is always plain before bonding in graphite $\rightarrow$ diamond transformation, but the graphyne layer is wrinkled at the barrier peak. This finding further confirms that graphyne is more easily deformed than graphene because of the presence of acetylenic linkages.

Covalent-bonded graphyne polymers possess tunable densities that ranged from the $1.9 \mathrm{~g} / \mathrm{cm}^{3}$ of $\mathrm{hP16}$-carbon (which approaches to that of graphite) to $3.3 \mathrm{~g} / \mathrm{cm}^{3}$ of $o P 12$-carbon (which is close to that of diamond). Therefore, these polymers will show various properties.

Graphite is semimetallic, whereas diamond is semiconductive with a large band gap. Theoretical simulations demonstrate that graphynes are either semiconductive or semimetallic [40-43]. Covalent-bonded graphyne polymers readily show more abundant electronic properties relative to graphyne (Fig. 6). The $h P 12$-carbon and 
oI16-carbon are semiconductive, whereas the corresponding 6,6,6,-graphyne and $18,18,18$-graphyne are metallic, which is similar to the change from graphite to diamond. However, the other 18,18,18-graphyne production, $h P 16$-carbon, inherits the metallic properties, and similar phenomena happens on oC12-carbon and $o C 24$ carbon. The $t P 6$-carbon, $o P 12$-carbon, and $m C 16$-carbon show analogous metallic properties with the parent graphynes. The $o C 12$-carbon and oI16-carbon notably possess rather narrow band gaps of just 0.29 and $0.57 \mathrm{eV}$, respectively. This finding is significant in various applications, such as high-speed nanoelectronics, transparent electrodes, and chemical sensors.
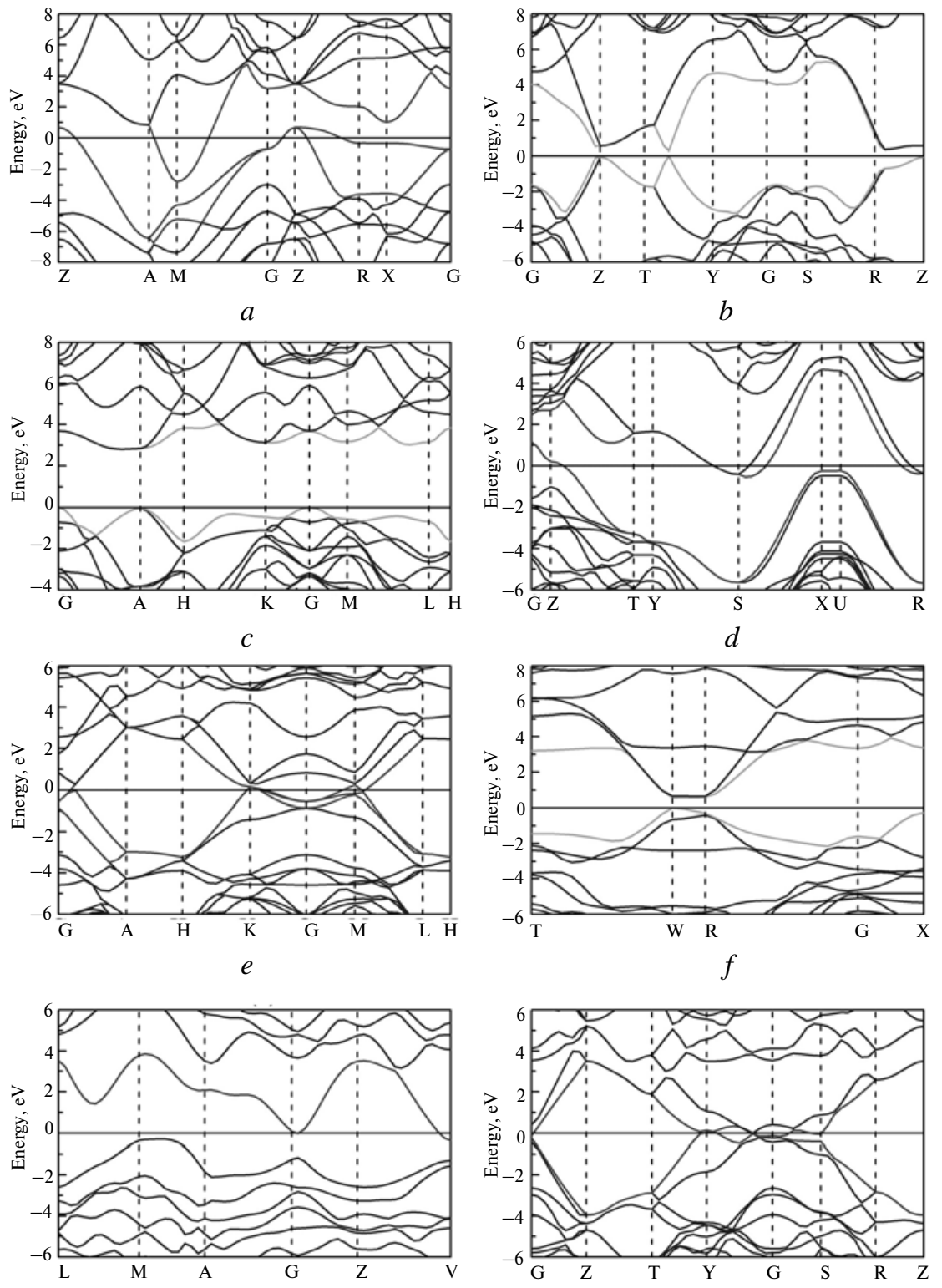

$g$

$h$

Fig. 6. Calculated electronic band structures of (a) tP6-carbon, (b) oC12-carbon, (c) hP12carbon, (d) oP12-carbon, (e) hP16-carbon, (f) oI16-carbon, (g) mC16-carbon, and $(h) o C 24-$ carbon at ambient pressure. 
Graphene is known to be one of the strongest materials with an ultrahigh inplane Young's modulus of $\sim 1 \mathrm{TPa}$ [44]. However, the introduced acetylenic linkages soften graphyne, which results in decreased Young's modulus, shear modulus, and bulk modulus (i.e., the so-called layer modulus) to half of that of graphene [14]. For the newly designed covalent-bonded graphyne polymers (Table 3), the Young's modulus that is quasi-horizontal to the graphyne layers change greatly from 102.2 to $768.9 \mathrm{GPa}$; this parameter closely depends on the ratio of acetylenic linkages in the parent graphyne and the wrinkle vertical to the graphyne layers. The Young's modulus quasi-vertical to the graphyne sheet is significantly high, and that of all covalent-bonded graphyne polymers (except $t P 6$ carbon and $h P 16$-carbon) possess the Young's modulus of about $1 \mathrm{TPa}$.

Table 3. Simulated Young's modulus quasi-horizontal $\left(Y_{h}\right)$ and quasi-vertical $\left(Y_{v}\right)$ to the graphyne sheet, and Vickers hardness $\left(H_{v}\right)$ of carbon allotropes

\begin{tabular}{c|c|c|c}
\hline Structure & $Y_{h}, \mathrm{GPa}$ & $Y_{v}, \mathrm{GPa}$ & $H_{V}, \mathrm{GPa}$ \\
\hline tP6-carbon & 731.0 & 731.0 & 16.8 \\
oC12-carbon & 190.8 & 1177.9 & 31.9 \\
hP12-carbon & 545.5 & 1096.6 & 36.4 \\
oP12-carbon & 768.9 & 1195.2 & 42.2 \\
hP16-carbon & 99.6 & 741.5 & 11.1 \\
oI16-carbon & 102.2 & 907.2 & 15.4 \\
mC16-carbon & 436.9 & 1105.9 & 41.6 \\
oC24-carbon & 106.6 & 972.1 & 27.6 \\
\hline
\end{tabular}

Hardness is one of the fundamental mechanical properties of materials. Several theoretical models, such as the microscopic model based on bond resistance and the macroscopic model based on Pugh's modulus ratio, have been addressed to measure material hardness [1, 45, 46]. Bond resistance model [45] presents difficulties in estimating the hardness of complex crystals (such as the covalentbonded graphyne polymers) because of numerous planar $s p^{2}$-hybridization bonds. Vickers hardness is calculated using the modified macroscopic model, i.e., $H_{V}=$ $0.92 k^{1.137} G^{0.708}$, where $k$ is equal to $G / B, G$ represents shear modulus and $B$ represents bulk modulus $[1,46]$. The $o P 12$-carbon and $m C 16$-carbon are superhard materials with hardness higher than $40 \mathrm{GPa}$. Although these materials exhibit less hardness than diamond, they show better ductility. The ratio $B / G$ has been widely used to check the ductility/brittleness of a crystal. Pugh [47] proposed that high (low) $B / G$ value is associated with ductility (brittleness), and the critical value is 1.75. All covalent-bonded graphyne polymers are more ductile than diamond (see Table 2), and $t P 6$-carbon and $h P 16$-carbon are ductile materials.

Raman spectroscopy is commonly used as a fingerprint in identifying a phase transformation. This method has been widely used in investigating CNT deformation and polymerization under pressure. In the current study, oP12-carbon, $h P 16$-carbon, and oI16-carbon are provided to explain transformation using Raman spectroscopy. The nature of graphyne triple bond (bonds II and VI in Fig. 7) is characterized by the unique Raman spectrum with the eigenfrequency of approximately $2200 \mathrm{~cm}^{-1}$ (marked squares), whereas these of graphite and diamond are $1582 \mathrm{~cm}^{-1}$ and $1332 \mathrm{~cm}^{-1}$, respectively. In the g-graphyne-II $\rightarrow o P 12$-carbon transformation, triple bonds (bond II) are polymerized into single bonds (bond I); 
this process results in the eigenfrequency redshift to $1762 \mathrm{~cm}^{-1}$ (marked triangles). In 18,18,18-graphyne $\rightarrow h P 16$-carbon, the triple bonds (bond $V I$ ) exclusively change into single bonds (bond III) with the eigenfrequency in graphyne redshift to $1597 \mathrm{~cm}^{-1}$, which approaches to that of graphite. However, the triple bonds in 18,18,18-graphyne are changed into two kinds of single bonds in oI16-carbon, i.e., the bonds $I V$ and $V$. The length of bond IV is $1.33 \AA$, which is a little shorter than that of graphite $(1.42 \AA)$ and corresponds to the Raman peak at $1775.4 \mathrm{~cm}^{-1}$. By contrast, the bond $V(1.40 \AA)$ is similar to graphite and corresponds to the Raman peak at $1430.9 \mathrm{~cm}^{-1}$.
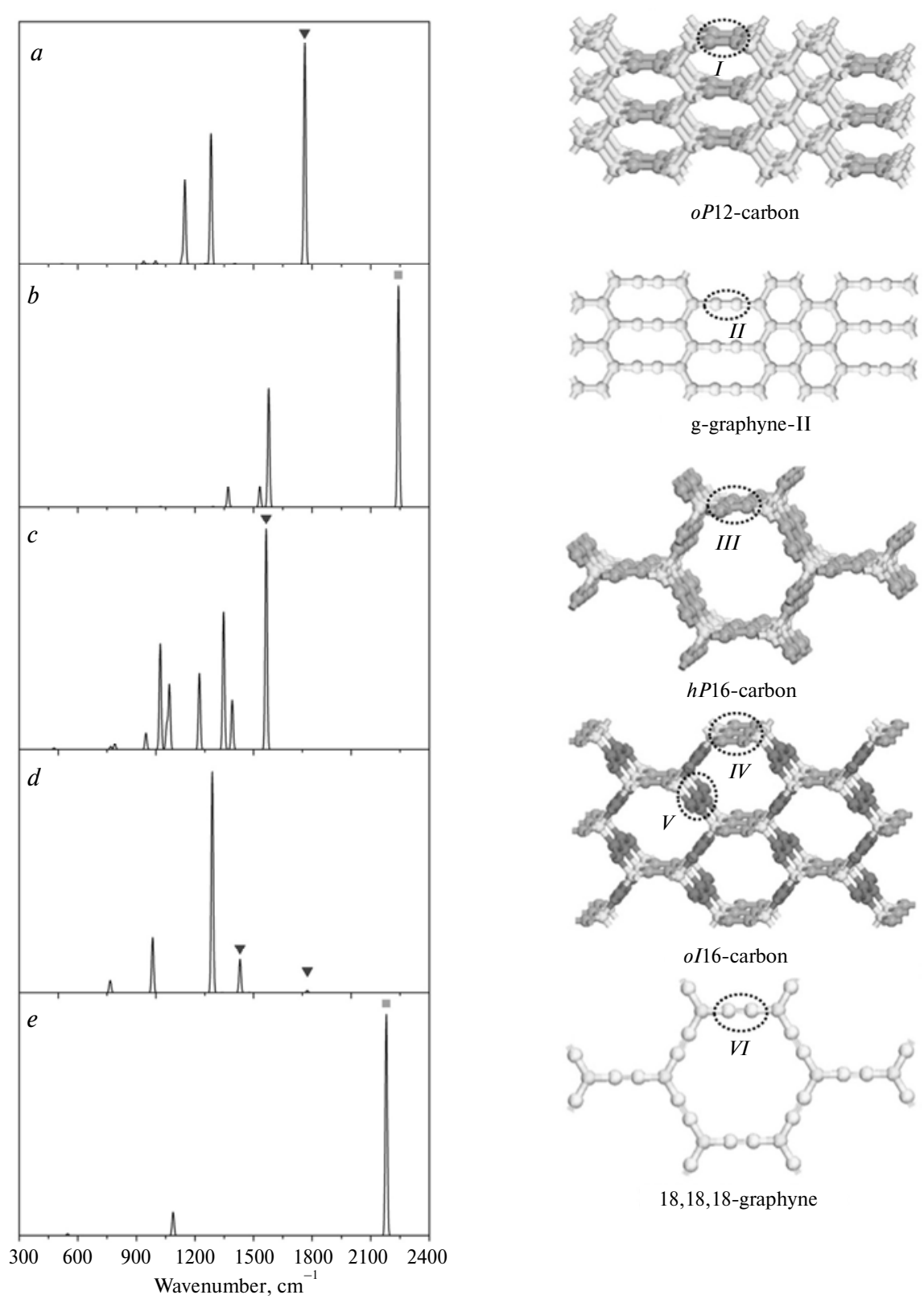

18,18,18-graphyne

Fig. 7. Simulated Raman spectra and corresponding crystal structures of $o P 12$-carbon, ggraphyne-II, $h P 16$-carbon, oI16-carbon, and 18,18,18-graphyne. The sticks in the circle of graphyne represent triple bonds, and the sticks in the circle of covalent-bonded graphyne polymers represent the single bonds converted from the triple bonds in parent graphyne. 


\section{CONCLUSIONS}

Covalent-bonded graphyne polymers with high hardness have been designed by employing crystal structure methods, USPEX and CALYPSO, based on the first principle calculations. Our research suggests graphyne as a novel precursor to synthesize hard and superhard carbon materials. As the variety of graphynes and phase transformation processes, results in there are various mechanically and dynamically stable covalent-bonded graphyne polymers with different densities. Covalent-bonded graphyne polymers are energetically more stable than corresponding graphynes, moreover, most of polymers are even more stable than fullerene $\mathrm{C}_{60}$ at ambient pressure. The phase transformation from graphite-like graphyne to covalent-bonded graphyne polymer encounters lower energy barrier than that from graphite to diamond. This finding suggests that more moderate pressure is required in graphyne $\rightarrow$ polymers than that of graphite $\rightarrow$ diamond transformation. Covalent-bonded graphyne polymers are either semiconductive or metallic with high hardness, Young's modulus, and bulk modulus. This finding indicates promising applications of covalent-bonded graphyne polymers in microelectronic devices, energy storage, wear-resistance coating, abrasives, and cutting and polishing tools.

\section{ACKNOWLEDGMENT}

This work was supported by NBRPC (Grant No. 2011CB808205) and NSFC (Grants Nos. 51121061, 91022029, 51332005, and 51272227).

Запропоновано вісім ковалентно-зв'язаних полімерів графана, отриманих за допомогою нещодавно розроблених методів USPEX $i$ CALYPSO, заснованих на розрахунках з перших принципів. Ці полімери енергетично більш вигідні, ніж відповідні графани під атмосферним тиском, і сім з них є більш стабільними, ніж фулерен $C_{60}$, що вказує на можливість їх існування. Механічна $i$ динамічна стабільність таких кристалічних структур підтверджуються розрахунком їх пружних констант і кривими дисперсї фононів відповідно. Нещодавно здійснене моделювання змінної комірки збудженої пружною зони показало, що перетворення графан $\rightarrow$ полімер відбувається при більш низькому енергетичному бар'єрі, ніж перетворення графіт $\rightarrow$ алмаз. Встановлено, шьо два полімера графана є надтвердими, а інші - твердими матеріалами. Ці полімери графана мають електронні властивості, що змінюються від металічних до напівпровідникових.

Ключові слова: полімери графана, твердість, електронні характери-

стики.

Предложены восемь ковалентно-связанных полимеров графана, полученных с помощью недавно разработанных методов USPEX и CALYPSO, основанных на расчетах из первых принципов. Эти полимеры энергетически более выгодны, чем соответствуюшие графаны при атмосферном давлении, и семь из них являются более стабильныли, чем фуллерен $C_{60}$, что указывает на возможность их существования. Механическая и динамическая стабильность таких кристаллических структур подтверждаются расчетом их упругих констант и кривыми дисперсии фононов соответственно. Недавно осуществленное моделирование переменной ячейки возбужденной упругой зоны показало, что превращение графан $\rightarrow$ полимер происходит при более низком энергетическом барьере, чем превращение графит $\rightarrow$ алмаз. Установлено, что два полимера графана являются сверхтвердыми, а другие - твердыми материалами. Эти полимеры графана имеют электронные свойства, изменяюшиеся от металлических до полупроводниковых.

теристики.

Ключевые слова: полимеры графана, твердость, электронные харак- 
1. Tian Y., Xu B., Zhao Z. Microscopic theory of hardness and design of novel superhard crystals // Int. J. Refract. Met. Hard Mater. - 2012. - 33, July. - P. 93-106.

2. Al-Khatatbeh Y., Lee K. K. M. From superhard to hard: A review of transition metal dioxides $\mathrm{TiO}_{2}, \mathrm{ZrO}_{2}$, and $\mathrm{HfO}_{2}$ hardness // J. Superhard Mater. - 2014. - 36, N 4. - P. 231-245.

3. Irifune T., Kurio A., Sakamoto S. et al. Materials: Ultrahard polycrystalline diamond from graphite // Nature. - 2003. - 421, N 6923. - P. 599-600.

4. Sumiya H., Irifune T. Indentation hardness of nano-polycrystalline diamond prepared from graphite by direct conversion // Diamond Relat. Mater. - 2004. - 13, N 10. - P. 1771-1776.

5. Schindler T. L., Vohra Y. K. A micro-Raman investigation of high-pressure quenched graphite // J. Phys.: Condens. Matter. - 1995. - 7, N 47. - P. L637-L642.

6. Chernozatonskii L. A., Serebryanaya N. R., Mavrin B. N. The superhard crystalline threedimensional polymerized $C_{60}$ phase // Chem. Phys. Lett. - 2000. - 316, N 3-4. - P. 199-204.

7. Yamanaka S., Kini N. S., Kubo A. et al. Topochemical 3D polymerization of $\mathrm{C}_{60}$ under high pressure at elevated temperatures // J. Am. Chem. Soc. - 2008. - 130, N 13. - P. 4303-4309.

8. Khabashesku V. N., Gu Z., Brinson B. et al. Polymerization of single-wall carbon nanotubes under high pressures and high temperatures // J. Phys. Chem. B. - 2002. - 106, N 43. P. 11155-11162.

9. Kumar R. S., Pravica M. G., Cornelius A. L. et al. X-ray Raman scattering studies on $\mathrm{C}_{60}$ fullerenes and multi-walled carbon nanotubes under pressure // Diamond Relat. Mater. 2007. - 16, N 4-7. - P. 1250-1253.

10. Baughman R. H., Eckhardt H., Kertesz M. Structureproperty predictions for new planar forms of carbon: layered phases containing $s p^{2}$ and sp atoms // J. Chem. Phys. - 1987. - 87, N 11. P. 6687-6699.

11. Haley M. M., Brand S. C., Pak J. J. Carbon networks based on dehydrobenzoannulenes: synthesis of graphdiyne substructures // Chem. Int. Ed. Engl. - 1997. - 36, N 2. - P. 836-838.

12. Kehoe J. M., Kiley J. H., English J. J. et al. Carbon networks based on dehydrobenzoannulenes. 3. Synthesis of graphyne substructures // Org. Lett. - 2000. - 2, N 7. - P. 969-972.

13. Li G., Li Y., Liu H. et al. Architecture of graphdiyne nanoscale films // Chem. Commun. 2010. - 46, N 19. - P. 3256-3258.

14. Ivanovskii A. L. Graphynes and graphdyines // Prog. Solid State Chem. - 2013. - 41, N 1-2. - P. 1-19.

15. Ducéré J.-M., Lepetit C., Chauvin R. Carbo-graphite: structural, mechanical, and electronic properties // J. Phys. Chem. C. - 2013. - 117, N 42. - P. 21671-21681.

16. Zheng Q., Luo G., Liu Q. et al. Structural and electronic properties of bilayer and trilayer graphdiyne // Nanoscale. - 2012. - 4, N 13. - P. 3990-3996.

17. Leenaerts O., Partoens B., Peeters F. M. Tunable double Dirac cone spectrum in bilayer a-graphyne // Appl. Phys. Lett. - 2013. - 103, art. 013105.

18. Hwang H. J., Koo J., Park M. et al. Multilayer Graphynes for Lithium Ion Battery Anode // J. Phys. Chem. C. - 2013. - 117, N 14. - P. 6919-6923.

19. Wang A., Li L., Wang X. et al. Graphyne-based carbon allotropes with tunable properties: From Dirac fermion to semiconductor // Diamond Relat. Mater. - 2014. - 41, N 1. - P. 65-72.

20. Bu H., Zhao M., Wang A., Wang X. First-principles prediction of the transition from graphdiyne to a superlattice of carbon nanotubes and graphene nanoribbons // Carbon. - 2013. - 65, December. - P. 341-348.

21. Wang Y., Lv J., Zhu L., Ma Y. CALYPSO: a method for crystal structure prediction // Comput. Phys. Commun. - 2012. - 183, N 10. - P. 2063-2070.

22. Oganov A. R. and Glass C. W. Crystal structure prediction using ab initio evolutionary techniques: principles and applications // J. Chem. Phys. - 2006. - 124, art. 244704.

23. Hu M., Tian F., Zhao Z. et al. Exotic Cubic Carbon Allotropes // J. Phys. Chem. C. - 2012. 116, N 45. - P. 24233-24238.

24. Zhao Z., Tian F., Dong X. et al. Tetragonal allotrope of group 14 elements // J. Am. Chem. Soc. - 2012. - 134, N 30. - P. 12362-12365.

25. Zhu Q., Zeng Q., Oganov A. R. Systematic search for low-enthalpy $s p^{3}$ carbon allotropes using evolutionary metadynamics // Phys. Rev. B. - 2012. - 85, art. 201407(R).

26. Li Q., Ma Y., Oganov A. R. et al. Superhard Monoclinic Polymorph of Carbon // Phys. Rev. Lett. - 2009. - 102, art. 175506.

27. Clark S. J., Segall M. D., Pickard C. J. et al. First principles methods using CASTEP // Z. Kristallogr. - 2005. - 220, N 5/6. - P. 567-570.

28. Ceperley D. M., Alder B. J. Ground state of the electron gas by a stochastic method // Phys. Rev. Lett. - 1980. - 45, N 7. - P. 566-569. 
29. Perdew J. P., Zunger A. Self-interaction correction to density-functional approximations for many-electron systems // Phys. Rev. B. - 1981. - 23, N 10. - P. 5048-5079.

30. Monkhorst H. J., Pack J. D. Special points for Brillouin-zone integrations // Ibid.- 1976. 13, N 12. - P. 5188-5192.

31. Baroni S., Giannozzi P., Testa A. Green's-function approach to linear response in solids // Phys. Rev. Lett. - 1987. - 58, N 18. - P. 1861-1864.

32. Giannozzi P., de Gironcoli S., Pavone P., Baroni S. Ab initio calculation of phonon dispersions in semiconductors // Phys. Rev. B. - 1991. - 43, N 9. - P. 7231-7242.

33. Zhu Q., Zeng Q., Oganov A. R. Systematic search for low-enthalpy $s p^{3}$ carbon allotropes using evolutionary metadynamics // Ibid. - 2012. - 85, art. 201407.

34. Enyashin A. N. and Ivanovskii A. L. Graphene allotropes // Phys. Status Solidi. B. - 2011. 248, N 8. - P. 1879-1883.

35. Zhang S., Wang Q., Chen X., Jena P. Stable three-dimensional metallic carbon with interlocking hexagons // Proc. Natl. Acad. Sci. USA. - 2013. - 110, N 47. - P. 18809-18813.

36. Zhao Z., Xu B., Wang L.-M. et al. Three Dimensional Carbon-Nanotube Polymers // ACS Nano. - 2011. - 5, N 9. - P. 7226-7234.

37. Nye J. F. Physical Properties of Crystals. - Oxford University Press: Oxford, 1985.

38. Hu M., Zhao Z., Tian F. et al. Compressed carbon nanotubes: a family of new multifunctional carbon allotropes // Sci. Rep. - 2013. - 3, art. 1331.

39. Fahy S., Louie S. G. Cohen M. L. Pseudopotential total-energy study of the transition from rhombohedral graphite to diamond // Phys. Rev. B. - 1986. - 34, N 2. - P. 1191.

40. Narita N., Nagai S., Suzuki S., Nakao K. Optimized geometries and electronic structures of graphyne and its family // Ibid. - 1998. - 58, N 16. - P. 11009-11014.

41. Kang J., Li J., Wu F. et al. Elastic, electronic, and optical properties of two-dimensional graphyne sheet // J. Phys. Chem. C. - 2011. - 115, N 42. - P. 20466-20470.

42. Malko D., Neiss C., Viñes F., Görling A. Competition for graphene: graphynes with direction-dependent Dirac cones // Phys. Rev. Lett. - 2012. - 108, art. 086804.

43. Wujcik E. K., Monty C. N. Nanotechnology for implantable sensors: carbon nanotubes and graphene in medicine // WIREs Nanomed Nanobiotechnol. - 2013. - 5, N 3. - P. 233-249.

44. Liu F., Ming P., Li J. Ab initio calculation of ideal strength and phonon instability of graphene under tension // Phys. Rev. B. - 2007. - 76, art. 064120.

45. Gao F., He J., Wu E. et al. Hardness of covalent crystals // Phys. Rev. Lett. - 2003. - 91, N 1. - P. 015502.

46. Chen X.-Q., Niu H., Li D., Li Y. Modeling hardness of polycrystalline materials and bulk metallic glasses // Intermetallics. - 2011. - 19, N 9. - P. 1275-1281.

47. Pugh S. F. XCII. Relations between the elastic moduli and the plastic properties of polycrystalline pure metals // Phil. Mag. - 1954. - 45, N 367. - P. 823-843.

State Key Laboratory of Metastable Materials Science and Technology, _ Received 27.03.14 Yanshan University, Qinhuangdao, P. R. China 